\title{
12. Family size for a living wage
}

\section{PART I. BACKGROUND}

There is a broad consensus that 'living wage is a family concept. A worker should be able to support a family on a living wage' (Anker, 2011, p. 49). This consensus is incorporated in typical living wage definitions such as the Global Living Wage Coalition (GLWC) definition indicated in Chapter 1. The larger the reference family size, the higher the living wage estimate.

This chapter discusses how to determine an appropriate family size to use to estimate a living wage for a particular country and location - called the reference family size. Determining an appropriate reference family size for a living wage is not a simple arithmetic calculation. It requires judgment and should be based on different types of information, since each type has advantages and disadvantages/biases.

Section 12.1 discusses the type of family that a living wage should be able to support, and Section 12.2 discusses how to determine an appropriate reference size family for a living wage. Section 12.3 discusses why it is sometimes a good idea to add additional funds so that workers are able to help parents and relatives since many workers in developing countries have a social/cultural obligation to provide such support. Sections 12.4-12.6 provide examples.

\section{PART II. CONCEPTUAL FRAMEWORK}

\subsection{Definition of Family}

While a living wage needs to support a worker and his or her family, there are different definitions of family. We use the immediate family of a worker consisting of a worker, spouse or partner, and children - and do not include a worker's parents or extended family members - although in countries and societies where cultural norms as regards financial assistance to parents and/or extended family members are very strong, including some funds for this is warranted (see Section 12.3). 


\subsubsection{Difference between family and household}

Household and family are related but different concepts. In addition, the definition of household varies from survey to survey (e.g. sleep under same roof, or eat from a common pot, or share livelihoods, or some combination of these). This means that 'household' and 'family' are not interchangeable even though they are often used in this way. ${ }^{1}$

The terms household and family are not always used consistently in the literature. A household is usually defined as a group of persons (or one person) who make common provision for food, shelter, and other essentials for living, but practices [on how household is measured] vary significantly among countries. As a consequence, measures of household size and composition obtained from censuses or other sources in different countries are sometimes not directly comparable. The term family is used even less consistently. In the social science literature and in common usage 'family' refers to a group of kin - persons related by blood, marriage or adoption. (Bongaarts, 2001)

Therefore, average household size observed in a particular household survey does not necessarily provide a good measure of an appropriate reference family size for a living wage. For example, when a spouse migrates to a city for work, this reduces observed average household size in both rural and urban areas. It typically creates a new one-person household in the city and reduces average household size in rural areas - even though there is no change in the size of the family economic unit.

\subsubsection{For decency, workers should be able to afford to live with their family in the location where they work}

A common phenomenon in developing countries is for migrant workers to live without their families in cities or on/near farms mainly because they cannot afford to have their family live with them at a minimal level of decency on their current wages. We believe that for decency, a living wage should be sufficient for a worker to be able to afford to have their spouse/partner and children live with them in the locality where they work. Long periods of living apart create many health, safety, and psychological problems. Male workers living alone are especially prone to injuries and illnesses, including sexually transmitted diseases. Women workers living alone are especially vulnerable to violence and sexual assault. All workers living alone have added stress from separation from family. Children of migrant workers who are left behind are deprived of being brought up by parents.

For these reasons, our methodology assumes that a living wage needs to be high enough for workers to be able to afford to live with their family in the area where they work. It is not that workers must live with their family or that it is unacceptable when workers choose to live separately - it is 
rather that the decency concept of a living wage implies, in our opinion, that workers should have the financial means to be able to afford to have their family live with them. We do not believe that many people in the world would consider it decent for workers to have no choice but to live separately from their spouse and children because wages are too low to allow for them to live together.

Yet in many countries, it is common for workers to have no alternative but to live separately from their family for long periods of time because of low wages. This is especially common for workers who move to work in a city or on a plantation. Many migrant workers live without their family in slums. It is also common for migrant workers to live with unrelated workers in small dorm rooms.

The requirement that workers be able to afford to live with their immediate family if they so choose means that a living wage needs to be based on living standards and living costs in the location where workers are employed. It also means that it is not appropriate to estimate a separate living wage for migrants. This includes international migrants such as Haitians in Dominican Republic, or Mexicans in the United States. If a living wage was estimated based on living costs for families of international migrants in their country of origin, as has often been suggested to us, the living wage would be too low for a decent standard of living for nationals in their own country. More generally, having lower wages for migrant workers compared with non-migrant workers would likely lead to employers discriminating against the local population.

\section{PART III. APPROACH TO DETERMINING APPROPRIATE FAMILY SIZE FOR ESTIMATING A LIVING WAGE}

\subsection{How to Determine Appropriate Family Size for Estimating Living Wage}

Three approaches have been used to determine family size for estimating a living wage: (i) number of children born per women, (ii) average household size, and (iii) a typical family size - often four (Anker, 2011). While all three approaches provide valuable information, each approach can be misleading regarding the appropriate reference family size for estimating a living wage. It is therefore important to look at several measures of family size and use judgment to decide on the reference family size for estimating a living wage. Appendix 12.1 provides a table to record and organize relevant secondary data. 


\subsubsection{Family size of four persons a common assumption}

Past living wage studies have often used four persons as the reference family size. ${ }^{2}$ There are several advantages to this assumption. First, family size of four is:

a relatively easy and uncontroversial assumption to use ... This assumption is widely used; it roughly represents population replacement; and it is reasonably consistent with fertility rates found in many developing countries. Use of a household size below four would imply that a living wage would not be sufficient to ensure survival of countries over the long run [without international migration], and this seems contrary to the idea of a living wage. (Anker, 2011, p. 45)

Our view is that four persons should generally be the minimum reference family size for estimating a living wage, although it is worth noting that researchers carrying out six living wage studies in China using our methodology felt that 3.5 persons was appropriate in light of China's one-child policy for many years, albeit with important exceptions.

A reference family size of four is, however, too small for many countries and locations where women have significantly more than two children. This is especially common in Sub-Saharan Africa where around $70 \%$ of countries have a total fertility rate of at least four. Furthermore, fertility rates are generally higher in rural than in urban areas (e.g. total fertility rate is 5.9 in rural Kenya compared with 4.6 in urban Kenya, see example below). All of this means that a living wage reference family size of four is too small for most of Sub-Saharan Africa and the Middle East and some other parts of the world such as Pakistan, and for many rural areas in developing countries.

\subsubsection{Average household size}

Average household size is a useful statistic for determining a living wage reference family size, but it needs to be adjusted before it is used for this purpose. It might seem common sense to use average household size to estimate a living wage, as average household size would seem to represent typical family responsibilities. Indeed, it is common for other methodologies to use average household size to estimate living wages (Anker, 2011) ${ }^{3}$ and poverty lines in developing countries (Tabatabai, 1996).

There are, however, several problems with using average household size from surveys and censuses as the living wage reference family size. First, household and family are different concepts as explained above. Second, average household size observed in surveys and censuses, is affected by the definition of household used. Third, average urban household size is significantly reduced by migration whereas average family size for a living wage should not be affected by this. Fourth, average household size is 
reduced by the proportion of households without children (such as singleperson households) even though such households are not relevant for estimating a living wage which is a family concept. Fifth, average household size is affected by the frequency of extended family households which include two or more nuclear families and so possibly more than two adult workers, despite the fact that our methodology is concerned with nuclear families with at most two workers.

The first two points above imply that average household size from a specific survey or census is not always a reliable measure of average family size - and so that several data sources should be used. The third, fourth, and fifth points above imply that average household size from surveys might provide an underestimate or overestimate of an appropriate living wage reference family size and so need to be adjusted.

12.2.2.1 Exclude single-person households when measuring average household size Before using data on household size, single-person households (which definitely do not include children) should be excluded, since they are not relevant for estimating a living wage which is a family concept. This can be important for urban areas in developing countries where many people move without their family in search of employment; this can also be important in higher income countries where many young adults support themselves.

12.2.2.2 Exclude especially large households when measuring average household size Before using data on household size, very large households (that almost always include multiple nuclear families) should be excluded, since living wage in our methodology is concerned with the wage required by a nuclear family with at most two full-time earners. This can be an important adjustment for countries where extended families are common. Pakistan provides a good example of this. Average urban household size is 6.6 but 5.7 when single person households and very large households are excluded. A reasonable way of identifying households that are likely to include more than one nuclear family is to exclude households with more than the sum of the total fertility rate plus 5 , thereby allowing for three additional children to represent households with unusually high fertility plus two parents. For example, if the total fertility rate was 2 , households with eight or more members would be excluded when calculating average household size. If the total fertility rate was 3 , households with nine or more members would be excluded. 


\subsubsection{Number of children born and surviving per woman}

12.2.3.1 Number of children born per woman (total fertility rate) Total fertility rate (TFR) indicates the number of children women typically have over their lifetime. ${ }^{4}$ This is an important determinant of typical family size, since this can be thought to equal the total fertility rate plus two adults. For example, typical family size could be considered to be four when total fertility rate is 2 (i.e. two children and two adults), although in countries and locations with very high fertility rates or high mortality rates, the total fertility rate overestimates the number of children in a family at any point in time.

12.2.3.2 Taking child mortality into consideration A sizable number of children die in some countries. For example in rural Malawi where infant mortality rate is $7.3 \%$, mortality rate for ages $1-4$ is $6.1 \%$ (National Statistical Office and ICF Macro, 2011), and total fertility rate is 5.5 (World Bank, 2016), approximately 0.75 births die by age 5 for a typical woman. This means that the total fertility rate overstates the number of children needing to be supported in countries with high child mortality. For this reason, the total fertility rate needs to be adjusted for child mortality to estimate the typical number of surviving children per woman. In countries with low child mortality rates, the total fertility rate does not overstate the number of children surviving by much. For example, only around 0.02 births would die by age 5 on average in Mauritius, which has a total fertility rate of 1.76 births and a child mortality rate of $1.4 \%$.

The following equation can be used to calculate the average number of surviving children per woman:

Average number of surviving children $=$ TFR $\times(1-$ child mortality rate per 100 births)

12.2.3.3 Number of children less than age 18 per woman changes over time especially in high fertility countries The number of children that couples are responsible for starts at zero, increases as children are born, and decreases with child mortality and when children reach majority and move away to start their own life. This means that the number of children less than age 18 in a family is often lower than the number of children that are born and survive. This difference is especially large in countries with high fertility where children are necessarily born over a longer period of time.

To get an idea of how many children under age 18 that women have at different points in time in high fertility countries, we estimated this for 
non-metropolitan urban areas of Kenya using the following reasonable assumptions: (i) child-rearing period is 30 years; (ii) total fertility rate is 4; (iii) child mortality rate is $7.3 \%$; and (iv) average birth interval is three years. We found in this example that even though the total fertility rate is four, women have on average:

- Between 3 and 4 children under age 18 (3.7 on average) for 9 years (30\% of the time)

- Between 2 and 3 children under age 18 (2.8 children on average) for 6 years $(20 \%$ of the time), and

- Less than 2 children under age 18 for 15 years ( $50 \%$ of the time)

This exercise shows that despite a total fertility rate of 4 , women have between three and four children who are less than age 18 only around $30 \%$ of the time and approximately three children who are less than age 18 only around $20 \%$ of the time. From this exercise, it is clear that a family size of six (based on a total fertility rate of four plus two parents) significantly overstates what would be a reasonable living wage reference family size. We felt that five persons was reasonable in this case, because women have between three to four children under age 18 for around 15 years. It is worth noting that a family size of five was consistent with statistics on adjusted average household size for this area of Kenya.

\subsubsection{Important to consider rural-urban differences in family size}

Family size is often quite different in rural and urban areas in developing countries. For this reason, separate reference family sizes for rural and urban areas in a country are often warranted for estimating a living wage. According to Demographic and Health Surveys from around 2000, average household size was 5.4 in rural Asia compared with 4.9 in urban Asia; 5.0 in rural Latin America compared with 4.6 in urban Latin America; 6.1 in rural Near East/Middle East compared with 5.4 in urban Near East/Middle East; and 5.3 in rural Sub-Sahara Africa compared with 5.1 in urban Sub-Sahara Africa (Bongaarts, 2001).

\subsubsection{Drawing it all together to determine a living wage reference family size}

Judgment is required to decide on an appropriate family size to use to estimate a living wage for a particular country and location - although it is worth noting that an appropriate reference family size for most locations is generally uncontroversial. Three ways of determining an appropriate reference family size were discussed above along with possible problems and biases. We recommend using information from all three approaches to help 
decide on an appropriate reference family size, since all three approaches provide insights - while keeping in mind their advantages and biases. In summary we recommend that:

- The minimum family size used to estimate a living wage should be 4 persons, because smaller family sizes would not allow for population reproduction and so eventual survival of a country; 3.5 persons could be used in exceptional circumstances such as in urban China that has had a one child policy for decades.

- The maximum reference family size used to estimate a living wage in locations with very high fertility should be 6 persons.

- Family size should be expressed in half persons (i.e. 3.5, 4, 4.5, 5. 5.5, 6) in recognition of the fact that judgment is required to determine an appropriate reference family size.

Four persons is likely to be the most common family size for urban areas of developing countries outside Sub-Sahara Africa and the Middle East. A family size of 4.5 or 5 persons is likely to be common for rural areas around the world and for urban areas of Sub-Sahara Africa. A family size of 5.5 or 6 is likely to be restricted mostly to rural Sub-Saharan Africa and parts of the Middle East and Asia.

\subsection{Possible Need to Include Additional Funds to Assist Parents and Relatives Outside Nuclear Family}

Workers in many countries, even married workers, are expected to help support their parents. In addition, cultural norms in many developing countries require workers to help other relatives and share resources. Such a cultural norm is very strong in Sub-Sahara Africa where anyone with money is expected to share with relatives, and requests for money from relatives cannot be rejected. This means that many workers are more or less required to help parents and other relatives - if these workers are to remain part of their society.

In locations where there are very strong social/cultural norms of helping parents or other relatives more generally, we feel that it is reasonable and appropriate to include a small separate expense category for this. Without some additional funds for helping parents and other relatives in many developing countries, workers would not have sufficient income on a living wage to be able to afford a decent living standard for their own immediate family. It is preferable to include some funds for this compared with increasing the family size needing to be supported by a living wage because extended families are amorphous, and it is neither reasonable nor realistic 
in our opinion to expect companies to support an open-ended number of extended family members.

We feel that $5 \%$ or the value of one workday per month at a living wage represents a reasonable and conservative amount for this. Such an amount is much lower than the tithe given to religious organizations by many people around the world. Also, including a modest sum for assistance to relatives helps justify any decision to use a conservative family size as well as any decision not to include parents or other relatives in the reference family size. Regardless, it is important to justify including some funds for helping parents and other relatives in a living wage report to convince possible skeptics.

\section{PART IV. EXAMPLES}

To get an idea of how to decide on reference family size for a living wage, three examples are provided. One example has high fertility and high child mortality (non-metropolitan urban Kenya), one example has a total fertility rate just above 2 and low child mortality (rural Dominican Republic), and one example has low fertility and low child mortality (urban Vietnam).

\subsection{Example 1: Reference Family Size for Urban Townships Surrounding Lake Naivasha, Kenya (High Fertility and High Child Mortality)}

A major challenge to determining a reference family size for this location was that statistics for urban Kenya are highly influenced by the situation in large metropolitan cities such as Mombasa and Nairobi where fertility rates are lower than in non-metropolitan urban areas such as the townships surrounding Lake Naivasha. We used a combination of urban and rural demographic measures to help determine reference family size because the study area was demographically speaking between rural areas and large cities.

\subsubsection{Adjusted average household size}

Average household size in Kenya differs greatly in rural and urban areas and between sources. According to the 2005/06 HIES (Kenyan National Bureau of Statistics, 2007), average household size for families with two or more persons was 4.6 in urban areas and 5.9 in rural areas (around 5.3 on average). Average family size excluding single-person households according to the 2008/09 DHS was substantially lower at 3.8 for urban areas and 5.0 for rural areas (around 4.4 on average). ${ }^{5}$ Averaging values from these 
two surveys implied slightly less than 5 person reference family size for the area near Lake Naivasha flower farms.

\subsubsection{Number of surviving children under age 18}

Total fertility rate (TFR) in Kenya was 2.9 in urban areas, and 5.2 in rural areas (KNBS 2010) - with TFR falling over time. Since the townships surrounding Lake Naivasha consisted mainly of migrants from rural areas, and since the total fertility rate of migrants is typically between the rate in the originating area (5.2) and the rate in the destination area (2.9), we concluded that the TFR in this area was around four, which implied a family size of around six persons assuming no mortality (two parents + four children).

Since close to 0.3 out of every 4 births die on average before age 5 (as child mortality rate for Kenya was $7.3 \%$ according to World Bank World Development Indicators), this implied 3.7 surviving children per family (and so implied a family size of 5.7) after adjusting for child mortality. However, since this many children are necessarily born over a long period of time, there were typically around three children below age 18 on average per family in this area, which implied a reference family size of around 5.

\subsubsection{Reference family size for non-metropolitan urban Kenya}

In summary, since there were no estimates of family size or fertility for non-metropolitan urban Kenya, and since townships surrounding Lake Naivasha were demographically speaking between rural areas and large cities, we used a combination of urban and rural statistics to determine the reference family size. Both the adjusted average household size for households with two or more members, and the average number of surviving children under age 18 typically at home indicated a reference family size of around five persons.

\subsection{Example 2: Reference Family Size for Rural Dominican Republic (Total Fertility Rate Above Two and Low Mortality)}

\subsubsection{Adjusted total fertility rate}

Total fertility rate (TFR) in the Dominican Republic was 2.4 births and higher in rural areas than in urban areas by about 0.5 births according to the 2007 DHS (Centro de Estudios Sociales y Demográficos (CESDEM) and Macro International Inc., 2008). TFR had, however, been falling in recent years and so was probably somewhere around 2.5 births in rural Dominican Republic when the living wage study was undertaken. Child mortality in the Dominican Republic was $2.7 \%$, which reduced the estimated number of surviving children slightly from 2.5 to 2.43 . 


\subsubsection{Adjusted average household size}

Average adjusted household size was slightly less than 4 persons (3.9) for rural households excluding single-person households and households with 8 or more persons according to data from the 2007 DHS (Centro de Estudios Sociales y Demográficos (CESDEM) and Macro International Inc., 2008) and 2010 Household Census (Oficina Nacional de Estadistica and Ministero de Economia, Planificacion y Desarrollo, 2012).

\subsubsection{Reference family size for rural Dominican Republic}

In summary, both the adjusted average household size and the mortality adjusted total fertility rate were relatively consistent. Adjusted average household size (3.9) and adjusted total fertility rate (2.4) for rural areas taken together implied a reference family size of around four.

\subsection{Example 3: Reference Family Size for Urban Vietnam (Low Fertility and Low Mortality)}

\subsubsection{Adjusted average household size}

The average household size in urban Vietnam was 3.83 according to the 2012 Vietnam Household Living Standards Measurement Survey (Vietnam Government, General Statistics Office, 2012). The average household size excluding single-person households was 3.93, since around $3 \%$ of urban households were single-person households. ${ }^{6}$

\subsubsection{Adjusted total fertility rate}

The total fertility rate for urban Vietnam was 1.80 (2.05 for country and 2.20 for rural areas) according to the Vietnam Government General Statistics Office (2012). Since the child mortality rate was low $(2.4 \%$ according to World Bank (2015b), the number of surviving children in urban areas (1.76) and the number of children born (1.80) were almost the same. These data implied an average family size of 3.76 for urban Vietnam.

\subsubsection{Reference family size for urban Vietnam}

In summary, average adjusted household size in urban areas (3.93) as well as mortality adjusted total fertility in urban areas (3.76) both implied a reference family size of slightly less than 4 persons. It was clear that a living wage reference family size of 4 persons was appropriate for urban Vietnam. 


\section{NOTES}

1. Indian censuses provide an example of how 'family' and 'household' have been used interchangeably. 'Household' was used in 1872, 1881 and 1951 to the present while 'family' was used between 1891 and 1941.

2. Four of the 11 methodologies review in Anker (2011) used a family size of four. The typical family size for living wage estimates in United States in the early twentieth century was five persons (see Ryan, 1906).

3. Five of 11 living wage methodologies for developing countries reviewed in Anker (2011) used average household size.

4. Total fertility rate is 'a basic indicator of the level of fertility, calculated by summing age-specific birth rates over all reproductive ages. It may be interpreted as the expected number of children a woman who survives to the end of the reproductive age span will have during her lifetime if she experiences the given age-specific rates' (United Nations Statistics Division, 2016).

5. It was not possible to exclude especially large households from this calculation for Kenya as the largest household size reported was 7+ for the DHS and 9+ in the HIES.

6. It was not possible to exclude especially large households from the calculation for Vietnam as the largest household size reported was $6+$. 


\section{APPENDIX 12.1 RECORDING SECONDARY DATA ON REFERENCE FAMILY SIZE}

Table 12A.1 is a form for recording information needed to decide on the appropriate reference size family for a living wage. It is a good idea to collect information from several secondary data sources for household size, because reported household size is sensitive to definition and measurement. Note that for sources that indicate only average household size and not the distribution of households by number of members, only the average household size should be filled in with an indication that the distribution of households by number of members was not available. There may also be several sources available for TFR and U5MR. It is useful to list all available sources with an indication of which sources are the most relevant and reliable.

Table 12A.1 Table for recording total fertility rate, under 5 mortality rate, and household size distribution by number of household members

\begin{tabular}{|l|l|l|l|}
\hline 1. Total fertility rate (TFR) & Rural & Urban & $\begin{array}{l}\text { Location-specific } \\
\text { (specify) }\end{array}$ \\
\hline Source and year of data & & & \\
\hline & & & \\
\hline Conclusion and explanation of best TFR & & & \\
\hline 2. Under 5 mortality rate (U5MR) & Rural & Urban & $\begin{array}{l}\text { Location-specific } \\
\text { (specify) }\end{array}$ \\
\hline Source and year of data & & & \\
\hline & & & \\
\hline \multicolumn{4}{|l|}{ Conclusion and explanation of best } \\
U5MR & & & \\
\hline 3. Calculate mortality adjusted total fertility rate using 1 and 2 above \\
\hline Mortality adjusted TFR & & & \\
\hline
\end{tabular}


Table 12A.1 (continued)

\begin{tabular}{|l|l|l|l|}
\hline 4. Household size (use additional sheets for other sources or years) \\
\hline \multicolumn{2}{|l|}{ Source and year: } & \multicolumn{2}{|l|}{ \% of households } \\
\hline \# persons in household & Urban & \multicolumn{2}{l|}{$\begin{array}{l}\text { Location-specific } \\
\text { (specify) }\end{array}$} \\
\hline & & & \\
\hline 1 & & & \\
\hline 2 & & & \\
\hline 3 & & & \\
\hline 4 & & & \\
\hline 5 & & & \\
\hline 6 & & & \\
\hline 7 & & & \\
\hline 8 & & & \\
\hline 9 & & & \\
\hline 10 & & & \\
\hline 11 & & & \\
\hline $12+$ & & & \\
\hline Average household size & & \\
\hline $\begin{array}{l}\text { Average household size excluding 1 person } \\
\text { (with more than adjusted TFR }+5 \text { persons) }\end{array}$ & & & \\
\hline
\end{tabular}

